\title{
Correction to: Study of Energy Harvesting from Low-Frequency Vibration with Ferromagnetic Powder and Non-magnetic Fluid
}

\section{Haruhiko Shirai ${ }^{1} \cdot$ Hiromichi Mitamura ${ }^{1} \cdot$ Nobuaki Arai $^{2} \cdot$ Kazuyuki Moriya $^{1}$}

Published online: 20 December 2019

(C) Springer Science+Business Media, LLC, part of Springer Nature 2019

\section{Correction to: Plasmonics}

$$
\text { https://doi.org/10.1007/s11468-019-01067-9 }
$$

The original version of this article unfortunately contained a mistake. Reference \#38 is incorrect. The correct reference is given below.

38. Stroke frequency, but not swimming speed, is related to body size in free-ranging seabirds, pinnipeds and cetaceans; Sato K, Watanuki Y, Takahashi A, Patrick J.O, Miller P.J.O, Tanaka H, Kawabe R, Paul J, Ponganis P. J, Handrich Y, Akamatsu T, Watanabe Y, Mitani Y, Costa D.P, Bost C, Aoki K, Amano M, Trathan P, Shapiro A, Naito Y, Proceedings of The Royal Society (2006) https://doi.org/10. 1098/rspb.2006.0005

Publisher's Note Springer Nature remains neutral with regard to jurisdictional claims in published maps and institutional affiliations.

The online version of the original article can be found at https://doi.org/ 10.1007/s11468-019-01067-9

Haruhiko Shirai

shirai-h@bre.soc.i.kyoto-u.ac.jp

1 Graduate School of Informatics, Kyoto University,

Yoshida-Honmachi, Sakyo-ku, Kyoto, Japan

2 Field Science Education and Research Center, Kyoto University, Kitashirakawa Oiwake-cho, Sakyo-ku, Kyoto, Japan 